\title{
Assessment of Evidence Based Research on Internet Freedoms in Africa
}

\author{
Duncan Nyale \\ School of Computing \& Mathematics \\ The Cooperative University of Kenya \\ Nairobi, Kenya
}

\begin{abstract}
The main objective of this work was to identify and map studies relevant to internet freedoms in Africa and analyze them to identify patterns and trends distribution in order to nurture public debate and for due consideration by researchers and policy makers within the region. The need to focus on internet freedoms in Africa is because of limited research contextualizing internet freedoms in this region and challenges with public availability and accessibility of the research evidence. The goal is to enhance learning on the research evidence available that could be relevant in advancing internet policies in Africa. The search for studies on internet freedoms was based on identified themes and indicators of internet freedoms. The study methodology was online desk research with full focus on empirical studies between 2013-2019.
\end{abstract}

Keywords: ICT: - Information and Communications Technology, IP: - Internet Protocol, USPF: - Universal Service Provision Fund, Fintech: - Financial Technology, ICT4D: - ICT for Development, DL: - Digital Literacy, SSA: - Sub-Saharan Africa

\section{INTRODUCTION}

Scoping of this assignment required conceptualization (or clarification) of internet freedoms. What is internet freedom or internet related freedoms? Internet policies? This research therefore included policies, laws/regulations, strategies and actions that affect control, direction, access, and use of the internet. The search for studies on internet freedoms was based on several identified themes and indicators of internet freedoms in each study. These included:

Internet; digital rights and freedoms, freedom of expression on the internet

Studies on:

- Enablers and/or barriers to access and use of the internetcosts, infrastructure including use Universal Service Provision Fund (USPF)

- Enablers and barriers to freedom of expression and enjoyment of human rights

- Hindrances/challenges to digital content and creative works

- Information control on the internet and hate speech

- Internet and social media disruptions and censorshipeconomic and social costs to online businesses; alert systems, browser traffic, internet user testing

- Internet governance-administration, management and control

- Digital human/civil rights violations

Advocacy and civic engagement

Studies on:

- Use of the internet in promotion of or demand for transparency, government financial accountability, democracy (in all its forms), e-participation, fight against corruption

- Enablers and/or barriers of use of internet in civic engagement; transparency and accountability of budget processes

\section{Intellectual property on the internet}

Studies on:

- Use of IP on the internet;

- IP theft and protection; copyrights and piracy on the internet

- Opportunities/challenges relating to IP issues on the internet

\section{Internet/digital/cyber security}

Studies on:

- Enablers and/or hindrances to privacy on the internet, who is affected most-minorities

- Surveillance and interception of communications-internet, social media monitoring and mobile phones

- Cyber violence, bullying and its impact on online businesses; effects on minorities

\section{Tech entrepreneurship and incubation hubs}

Studies on:

Enables and/or barriers to use of the internet in tech innovation, start-ups, acceleration, investment hubs; innovation and entrepreneurship ecosystems; e-commerce; capacity and skills development

- Impact/effectiveness/functioning of tech entrepreneurship/incubation hubs/platforms

\section{ICT4D and poverty reduction}

Studies on;

- Enables and/or barriers to the use of internet for health, education/digital literacy, fintech, poverty reduction;

- Impact of internet freedoms on digital literacy-what works, what does not

- Digital inclusion and exclusion-youth ICT capacity development; training 


\section{OBJECTIVES}

The objectives of the study are as follows:

a) Mapping available research that will include collecting and cataloging existing, available and credible relevant research.

b) Analyze the collated data to identify patterns and classify the studies according to specified parameters.

c) Promote learning from existing research for stakeholders.

d) Promote the development of public policies from use of discrete pieces of research.

\section{METHODOLOGY}

The search for available studies on internet freedoms in Africa was conducted through online desk research focusing on empirical studies between 2013-2019. Search areas included:

- Online databases - Search Engines and Research Portals

- Institutional repositories - Research institutions, Universities, Advocacy organizations , Government agencies, International organizations and Professional associations/bodies

- Internet/ICT Regulatory Agencies - especially in SSA

- Social media - especially Twitter hash tags and Facebook posts of relevant internet forums

Sample search terms used to retrieve studies from the search areas included: Internet rights; digital rights; internet freedoms; digital freedoms; internet freedom of assembly; internet freedom; digital freedom of association; digital human; digital civil rights violations, internet violations; internet hate speech ,Internet governance; internet infrastructure management; internet administration; internet control; internet actors; content regulation; data protection; internet information control; fake news; misinformation and propaganda on the internet; internet and social media disruptions; internet shutdowns; internet censorship, IP regulation; content filtering; mandatory blocking of websites; end-user filtering; net neutrality; intermediary liability; network disruptions; Internet based entrepreneurship; e-commerce, internet-based start-ups; internet in tech innovation; internet investment hubs; innovation and entrepreneurship ecosystems; online businesses;

The articles retrieved were recorded and mapped according to the relevant criterion while factoring in crosscutting issues. The criterion used was:

\section{A. Themes}

Studies addressing the following themes were identified and recorded:

- Internet Governance - "The development and application by governments, the private sector and civil society, in their respective roles, of shared principles, norms, rules, decision-making procedures, and programs that shape the evolution and use of the internet". Includes infrastructure management, internet administration and control, actors, content regulation and data protection, information control on the internet-fake news, misinformation and propaganda, internet and social media disruptions, shutdowns and censorship, IP regulation including creative works and copyrights, content filtering, mandatory blocking of websites, end-user filtering, net neutrality, intermediary liability, network disruptions

- Internet/Digital Rights and Freedom - Right to use the Internet and digital technologies in relation to freedom of assembly and association including through social networks and platform, digital human and civil rights violations, hate speech on the internet

- Internet for Democracy - internet in civic engagement/politics, transparency, accountability, participation, advocacy and civic engagement, transparency, accountability and fight against corruption, e-participation and e-politics

- Internet Safety - Online and cyber security, data protection and privacy online, the right to the protection of personal data concerning him or her, piracy, IP theft, cyber violence and bullying, unlawful surveillance, monitoring and interception of users' online communications and information by state or non-state actors including social media

- Internet Based Entrepreneurship - E-commerce, internet-based start-ups, Internet in tech innovation, startups, acceleration, investment hubs, Innovation and entrepreneurship ecosystems, online businesses, businesses through the internet and e-commerce

- Internet Access, Affordability and Use - access and use of online spaces, trends in fixed line and mobile internet, access to information/content, universal access and broadband strategies, affordability, cost of access, imposing taxes and fees on internet users etc.

- Digital Literacy and Skills - Refers to "as a set of basic skills required for working with digital media, information processing and retrieval" (UNESCO, 2011). DL involves the ability to use software or operate a digital device as well as a large variety of complex cognitive, sociological, and emotional skills that end-users need in order to function effectively in a digitally driven environment. Also refers to the awareness, attitude and the ability of an individual to use digital tools for communication, expression and social action in specific life situations. There are multiple forms of digital literacies: information literacy (digital content), computer literacy (hardware and software), media literacy (Text, sound, image, video, social), communication literacy (non-linear interaction) and technology literacy (Tools for life situations).

- Information literacy can simply be distilled to refer to the ability to search, retrieve, manipulate, evaluate, synthesize and create digital content.

- Computer or ICT literacy refers to the ability to operate digital hardware and software.

- Media literacy encapsulates multiple streams of information and refers to the ability to interact with textual, sound, image, video and social medias

- Communication literacy refers to the ability to communicate in traditional and innovative mediums. This involves one-to-one communication in forms such as email, phone calls and short messages and 
also in the one-to-many form, where an individual also broadcasts content across multiple mediums to reach a broad array of interested parties.

- Technology literacy refers to the ability to adopt various technologies to a particular life situation. Thus, knowing which tool to select is an important ability and being able to adapt the tool to a particular context is equally important. These skills are particularly needed in the IT sector and these involve the ability to create/maintain new products, services and digital technologies used in the modern economy.

Note: Crosscutting issues in each of the themes; Gender, youth, marginalized groups, people with disabilities were noted.

\section{B. Categories(Indicators of Internet Freedom)}

Those that have implications on indicators of internet freedoms

- $\quad$ Trends in the themes identified above

- Enablers of internet freedoms (enhance people's use of the internet)

- Challenges to internet freedoms (makes it difficult to access and use internet)

- Impacts/Outcomes of programs and projects initiated to promote internet freedoms

- Solutions/Strategies to address internet freedoms such as pro-poor policies etc.

\section{Resources(Type of study)}

- Book

- Book Chapter

- Thesis/Dissertation

- $\quad$ Research report

- Journal Article

- Conference proceedings

- $\quad$ Policy brief

\section{Region Study was Conducted}

- Southern Africa- Studies conducted in/from countries in this region

- $\quad$ East Africa - Studies conducted in/from countries in this region

- West Africa - Studies conducted in/from countries in this region

- Central Africa - Studies conducted in/from countries in this region

- North Africa - Studies conducted in/from countries in this region

- $\quad$ Africa - Studies conducted in/from regions that cut cross or are outside the directly specified

\section{E. Quality of the Studies}

- High - Refereed or highly reviewed research evidence. This covers journals articles, book chapters, books. Have a high impact factor

- Medium - Have undergone some form of peer review. Includes conference Proceedings, Discussion Papers, Occasional Papers, Policy Briefs and Monographs, Theses/Dissertations (Postgraduate)

- $\quad$ Low - generally un-reviewed or minimal review. Includes research reports

\section{DATA ANALYSIS AND PRESENTATION}

Some 1040 articles were identified and analyzed as follows:

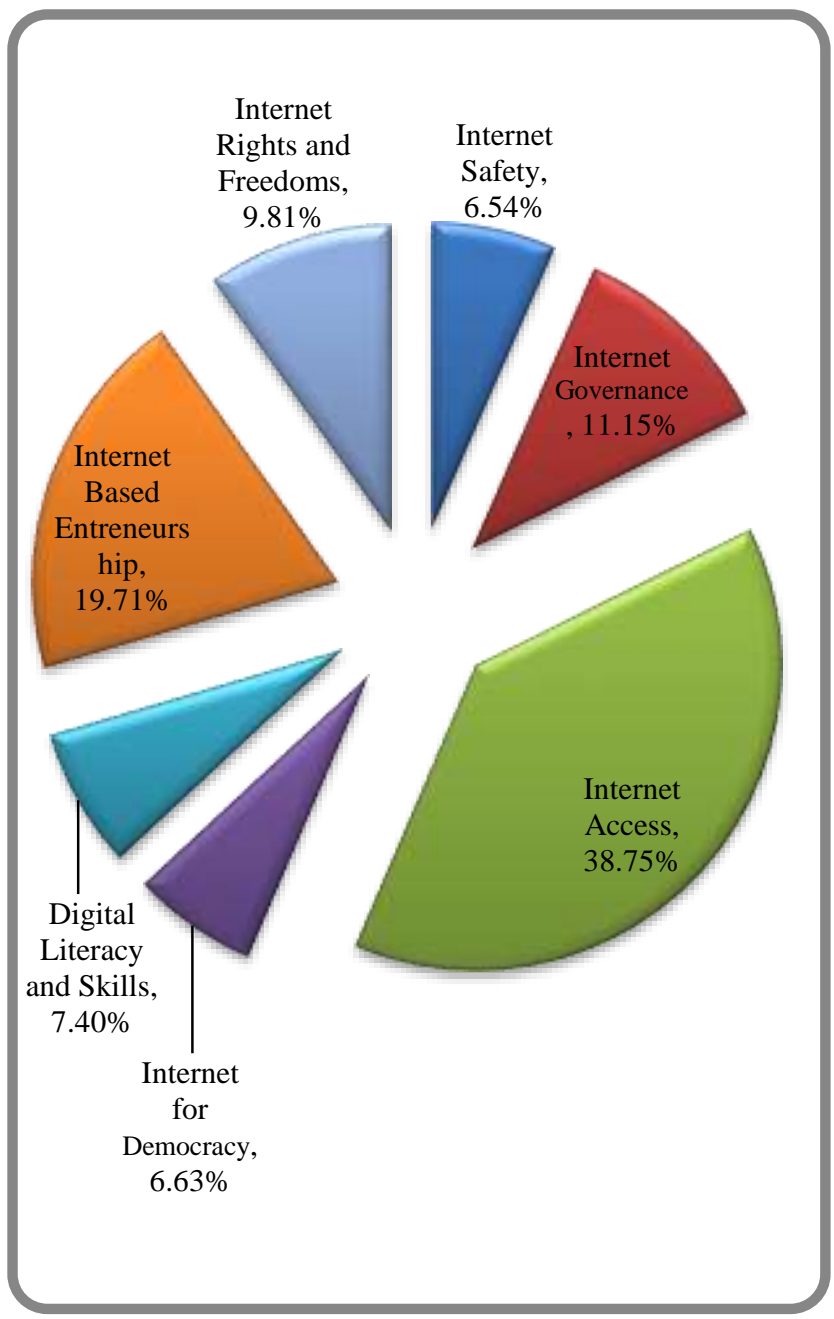

Figure 1. Studies Distribution by Theme 


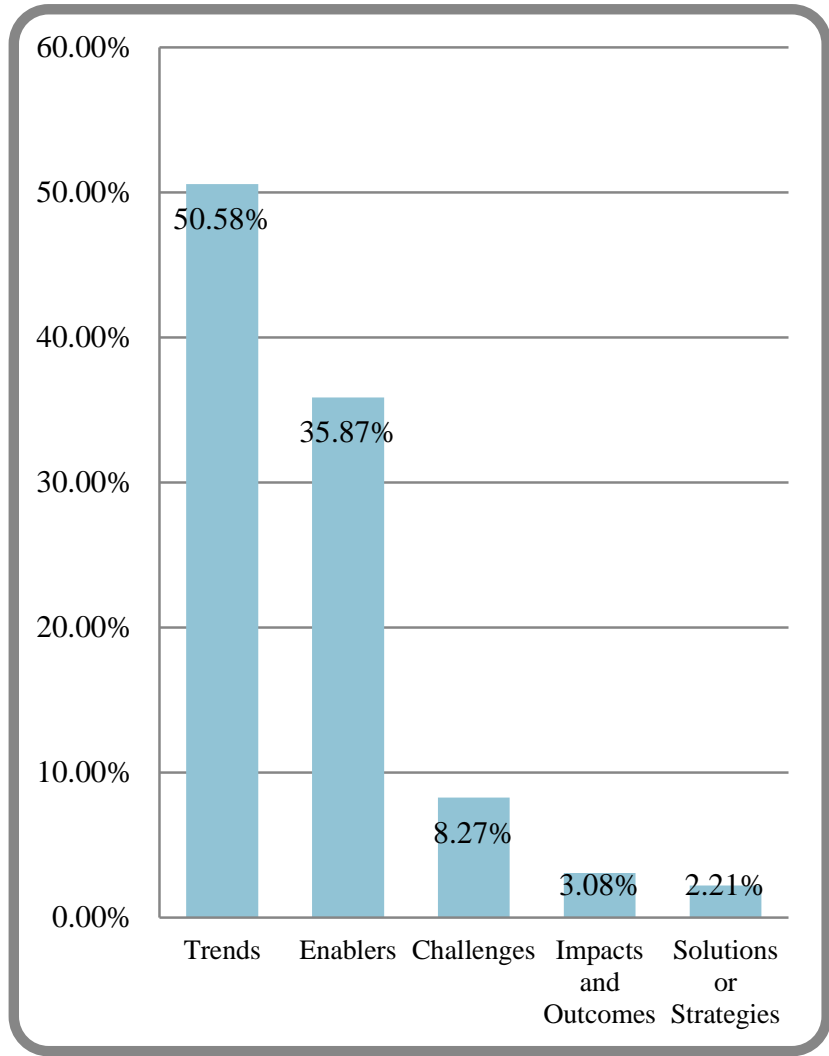

Figure 2. Studies Distribution by Categories (Indicators of Internet Freedom)

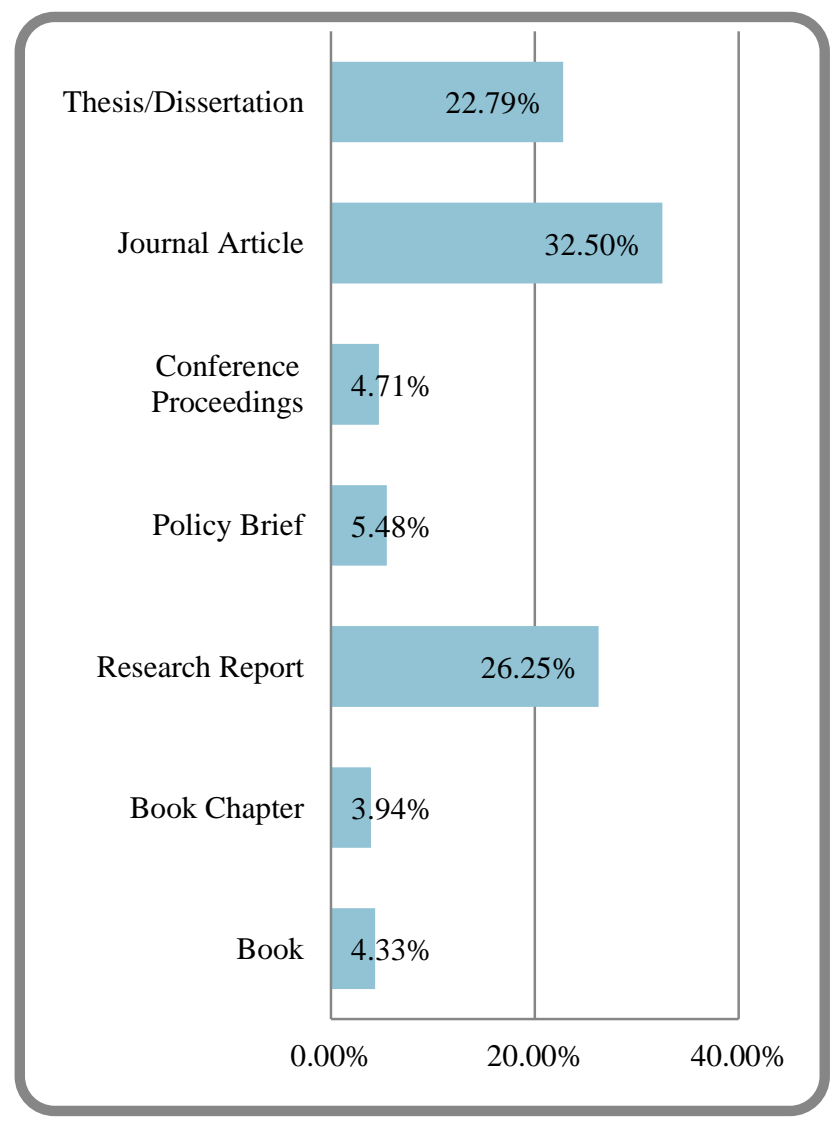

Figure 3. Studies Distribution by Resources (Type of study)

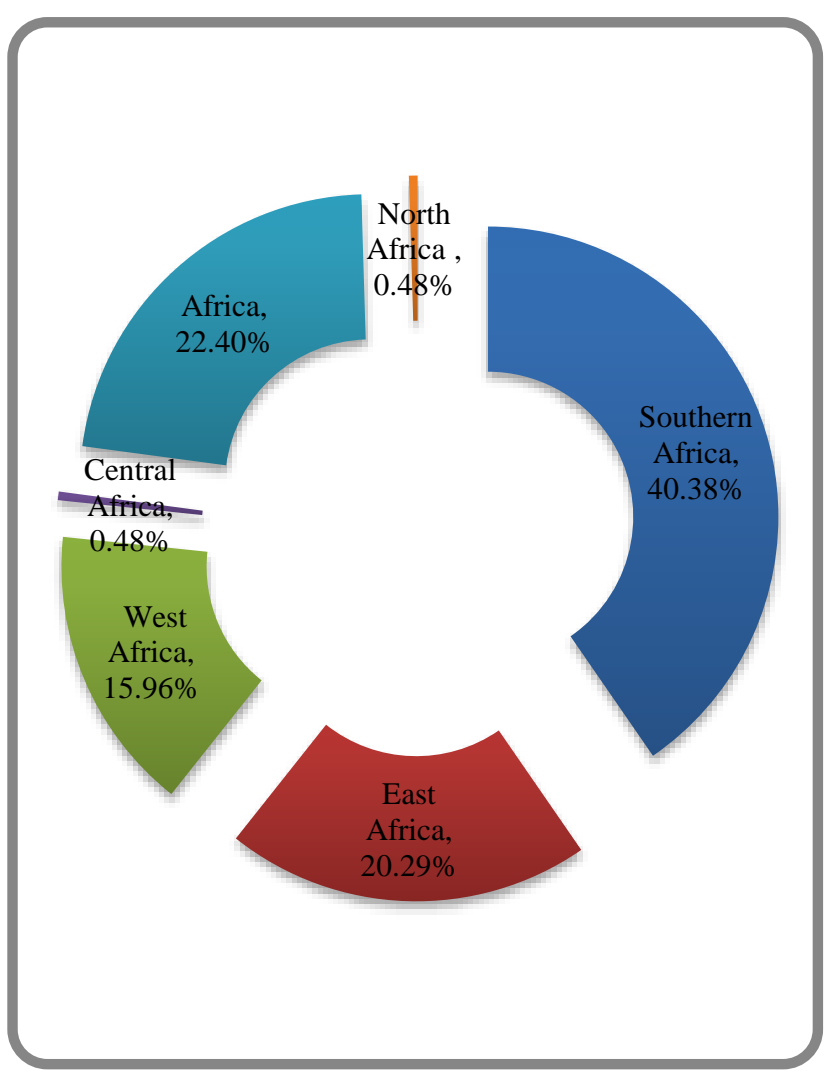

Figure 4. Studies Distribution by Region

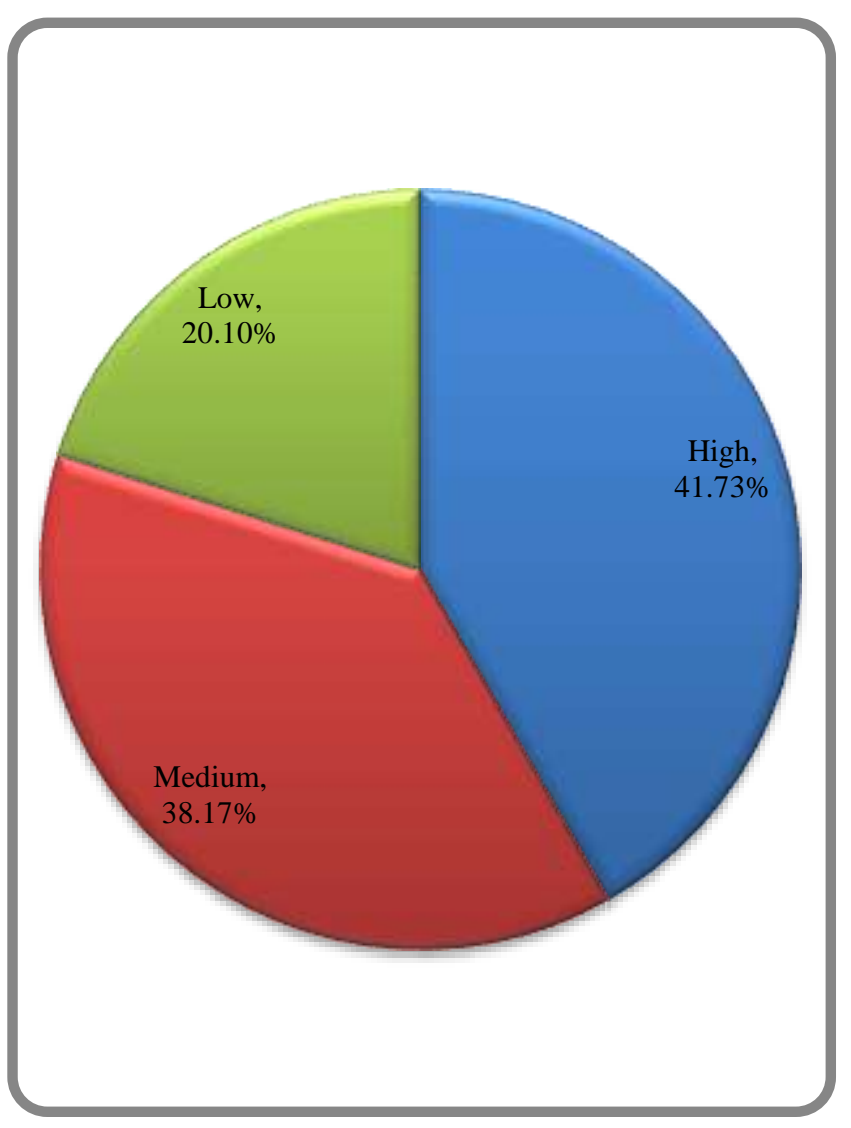

Figure 5. Studies Distribution by Quality 


\section{SUMMARY OF FINDINGS}

Some of the key patterns that emerged from this research are:

- Themes: Most of the studies are on Internet Access \& Use (38.75\%), while least are on Internet for democracy $(6.63 \%)$ and Internet Safety $(6.54 \%)$

- Categories: Most studies touched on Technological trends $(50.58 \%)$, while least studied were Impact \& Outcomes of application of internet technologies (3.08\%) and Solutions and Strategies to internet technology challenges. (2.21\%)

- Resources: Majority of articles are Research reports (26.25\%) and Thesis \& Dissertations $(22.79 \%)$ while least are Book Chapters (3.94\%)

- Regions: Most studies were in Southern Africa (40.38\%) while the least studied regions were Central and North Africa (both at $0.48 \%$ )

- Quality of Studies: Most studies were classified as High Quality (41.73\%); followed by medium Quality (38.17\%); and finally Low Quality studies (20.10\%).

\section{CONCLUSION}

The conclusion of this research revealed that although there is considerable research on internet freedoms in Africa, it is heavily skewed of some themes, categories and regions. There is need to expand the scope to equitably cover the areas that are currently under researched. It is the hope of this researcher that the studies distribution herein can assist future researchers on which areas to lay focus on and thus improve the body of knowledge while ensuring acceptable distribution of research on all the research areas identified and analyzed.

\section{RECOMMENDATIONS}

- More research should be conducted in the regions currently under researched.

- Focus should be directed more to High Quality (Peer reviewed) articles.

- More research is required on Digital Literacy \& skills, Internet safety and Internet for Democracy.

\section{SAMPLE SOURCES OF EVIDENCE}

[1] Google Scholar: http://scholar.google.com/

[2] Bielefeld Academic Search Engine (BASE): https://www.base-search.net/

[3] ScienceDirect: http://www.sciencedirect.com/

[4] WorldCat: https://www.worldcat.org/

[5] SpringerLink: https://link.springer.com/

[6] Google Books: https://books.google.com/

[7] CiteSeerx: https://citeseerx.ist.psu.edu/index
[8] Centre for Intellectual Property and Information Technology Law at Strathmore University (CIPIT): https://www.cipit.org/index.php/cipitresources

[9] University of Nairobi Digital Repository: http://erepository.uonbi.ac.ke/

[10] Collaboration on International ICT Policy for East and Southern Africa (CIPESA): https://cipesa.org/resources/

[11] Communication Authority of Kenya: http://www.ca.go.ke/index.php/research

[12] Uganda Communication Commission: http://www.ucc.co.ug/ and https://www.nita.go.ug/publications

[13] Social media especially Twitter hashtags and Facebook posts of relevant internet forums

[14] Combing through the hashtags \#InternetPolicyAfrica \#InternetFreedomsAfrica and identify any relevant ideas and sources of evidence.

[15] EbSCO: https://www.ebsco.com/products/researchdatabases

[16] JSTOR: https://www.jstor.org/

[17] Oxford Journals: https://academic.oup.com/journals/

[18] BudgIT: https://yourbudgit.com/data/publications/

[19] Taylor and Francis Online-Journals: https://www.tandfonline.com/openaccess/openjournals

[20] Google: https://www.google.com/

[21] Research ICT Africa: https://www.africaportal.org/content-partners/researchict-africa/

[22] Paradigm Initiative: https://paradigmhq.org/reports/

[23] Oxford Internet Institute: https://www.oii.ox.ac.uk/research/

[24] UNESCO: https://unesdoc.unesco.org/ark:/48223/pf0000188700

[25] UNECA: https://repository.uneca.org/

[26] AfDB: https://www.afdb.org/en/knowledge

[27] Co-Creation Hub: https://cchubnigeria.com/focus/

[28] AU: https://au.int/en/resources/filter

[29] ITU: https://www.itu.int/en/publications/Pages/default.aspx

[30] The Alliance for Affordable Internet (A4AI): https://a4ai.org/research/

[31] Kenya ICT Action Network (KICTANet): https://www.kictanet.or.ke/?page_id=40115

[32] Freedom House: https://freedomhouse.org/policyrecommendations

[33] Open Access Gov: https://www.openaccessgovernment.org/category/openaccess-news/research-innovation-news/

[34] The British Institute in Eastern Africa: https://www.biea.ac.uk/research/ 
International Journal of Computer Applications Technology and Research

Volume 9-Issue 05, 177-182, 2020, ISSN:-2319-8656

[35] CODESRIA: https://codesria.kohalibrary.com/cgibin/koha/opac-main.pl

[36] Article 19 Eastern Africa: https://www.article19.org/lawand-policy/

[37] African Institute for Development Policy Research and Dialogue (AFIDEP): https://uia.org/journals

[38] The African Centre for Technology Studies (ACTS): https://www.acts-net.org/research/projects

[39] African Technology Policy Studies (ATPS): https://atpsnet.org/publications/

[40] Africa Freedom of Information Centre (AFIC): https://ifex.org/resources/

[41] The Africa Institute of South Africa (AISA): http://www.ai.org.za/research

[42] Botswana Institute for Development Policy and Analysis (BIDPA): https://bidpa.bw/publications/

[43] Institute of Statistical, Social, and Economic Research (ISSER): https://www.poverty-action.org/research

[44] World Bank: https://www.worldbank.org/en/research 